\title{
Erratum
}

\section{Orthogonal Polynomial Trend Surfaces for Irregularly Spaced Data}

\section{E. H. Timothy Whitten ${ }^{1}$}

Table 4 of this paper which appeared in Mathematical Geology, Vol. 2, No. 2, 1970, should read as follows:

Table 4. Percentage of Total Corrected Sum of Squares Associated with Each Orthogonal Coefficient in Table 2

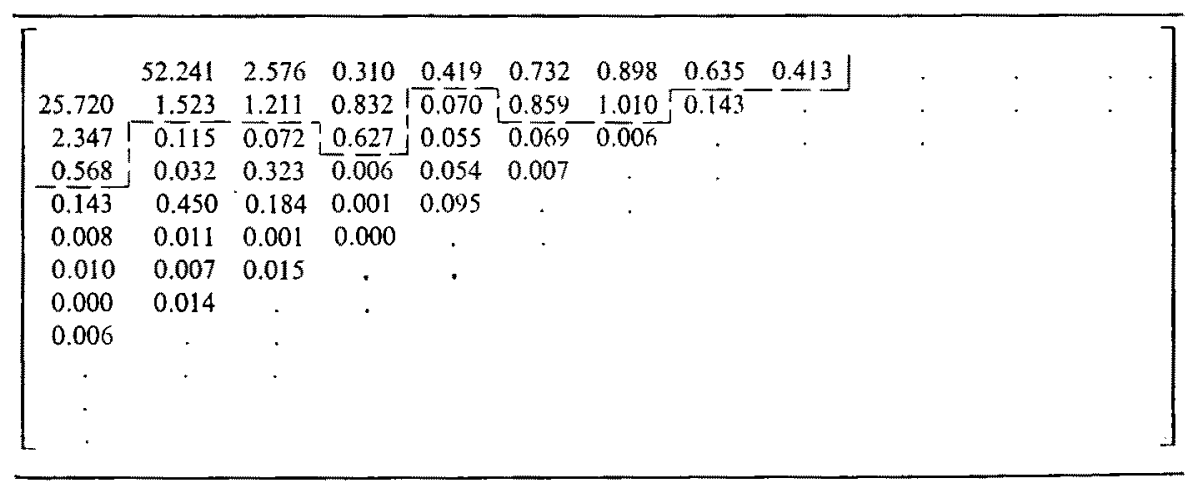

Table 3 should read as follows:

\footnotetext{
' Department of Geological Sciences, Northwestern University (USA).
} 


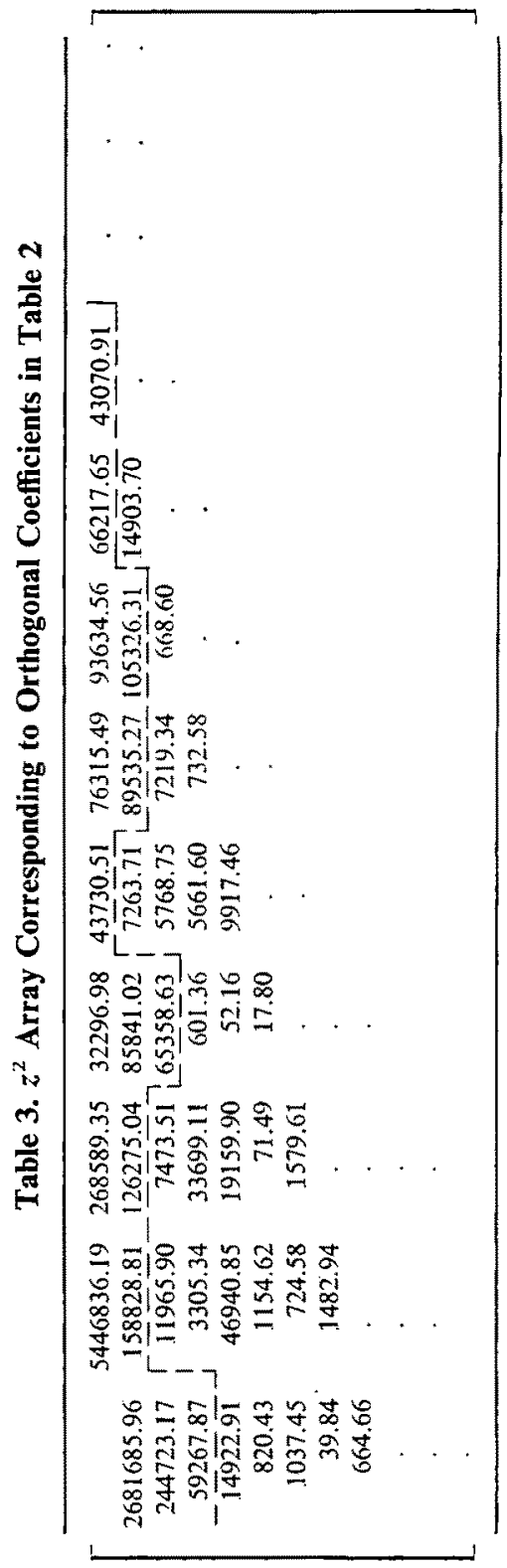

